\title{
Population dynamics of two endemic species in Aksu-Zhabagly State Nature Reserve
}

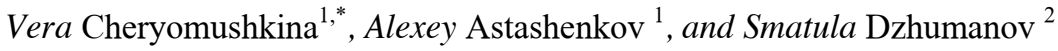 \\ ${ }^{1}$ Central Siberian Botanical Garden SB RAS, 630090 Novosibirsk, Russia \\ ${ }^{2}$ Aksu-Zhabagly State Nature Reserve, Zhabagly, 131610, Kazakhstan
}

\begin{abstract}
The structure of Allium pskemense and A. karataviense coenopopulations from the Aksu-Zhabagly State Nature Reserve was described. It was established that the ontogenetic spectrum of coenopopulations is left-sided with a maximum on immature individuals. This is due to good seed reproduction, rapid rates of development at the end of ontogenesis. It was shown that over a 10 -year period, there is a gradual aging of the coenopopulation, which is reflected in the shift of the peaks in the spectrum to the young generative (A.pskemense) and virginal (A. karataviense) groups. It was concluded that the sustainable development of coenopopulations will be in the case of a decrease in the number of the phytophages and successful regeneration by seed, which leads to a regular turnover of generations.
\end{abstract}

\section{Introduction}

The study of the causes and mechanisms of the long and sustainable existence of species at the population level is an urgent task in modern plant ecology. This is directly related to the conservation of biodiversity. Monitoring of coenopopulations (CPs), including the analysis of biomorphs, ontogenetic composition and demographic indicators, makes it possible to identify the features of dynamic processes reflecting the development of populations and the change of generations of the individuals. These studies are relevant in the era of increased anthropogenic load, and protected (reserved) biomes are unique testing grounds for such experimental studies.

In our work, two Central Asian onions Allium pskemense B. Fedtsch. and $A$. karataviense Regel were studied. Both grow on the Talas Alatau ridge and preserve in the Aksu-Zhabagly State Nature Reserve. These onions are rare and endangered species and are used for food, as ornamental plants and donors for the selection of new forms and cultivars [1]. In this regard, the purpose of the work is to study the structure of the species coenopopulations and its dynamics under the conditions of the reserve regime in the AksuZhabagly (Kazakhstan). A pskemense is an endemic of the Western Tien Shan [2], the range of $A$. karataviense extends from the Chu-Ili Mountains and the Western Tien Shan

\footnotetext{
${ }^{*}$ Corresponding author: cher.51@mail.ru
} 
ranges to the Darvaz and Alai ranges. Some researchers consider that $A$ karataviense is an endemic of the Syrdarya Karatau [3].

\section{Material and methods}

The structure of the coenopopulations was studied in 2006 and 2016 in the gorge of the Kshi-Kaindy river (A. karataviense) and in the canyon of the Aksu river (A.pskemense). The CP of A. pskemense was studied on a steep $\left(45^{\circ}\right)$ rocky slope descending to the Aksu river at an altitude of $1480 \mathrm{~m}$ above sea level. The grass cover is sparse: Ferula tenuisecta Korovin., Ferula renardii (Regel \& Schmalh.) Pimenov, Eremurus lactiflorus O. Fedtsch., Althaea nudiflora (Lindl.) Boiss., Cicer songaricum Stephan ex DC., Paraligusticum discolor (Ledeb.) Tikhom. other. The CP of A. karataviense was investigated on the scree located at $\mathrm{h}=1815 \mathrm{~m}$ above sea level. The plant group was composed of Lonicera tianshanica Pojark., Rosa kokanica (Regel) Regel ex Juz., Rosa webbiana Wall. ex Royle, Ziziphora clinopodioides Lam., Prangos pabularia Lindl., Megacarpaea orbiculata B. Fedtsch., Ferula penninervis Regel et Schmalh, Hordeum bulbosum L., Hypericum scabrum L. other.

The analysis of the ontogenetic structure of the CP was carried out according to the method of studying rare plants [4]. The ontogenetic states of the species individuals were identified on the basis of the previously described ontogeny [5-6]. The CP type was established according to the classification "delta-omega" by L.A. Zhivotovsky [7]. The ontogenetic spectrum of the CPs was defined as the ratio of different ontogenetic states plants, expressed as a percentage of the total number of the individuals [8]. The dynamic processes in the CP were characterized using the recovery index (Ib) and the speed of development $(\mathrm{V} \Delta)[9]$.

\section{Results and discussion}

A.pskemense belongs to rhizomatous-bulbous monocentric particulate loose bushgrass with oblique rhizome [6]. The duration of ontogenesis is 20-25 years, the duration of the pregenerative period is $4-5$ years. Vegetative reproduction occurs in the middle of the generative period. The individuals form compact clones. There are up to 2-6 daughter individuals (ramets) in a clone. There is no rejuvenation of ramets. They are aging at the same time as the clone. Such vegetative reproduction increase the life span of individuals in the generative period. Self-preservation of the CP occurs only by seeds.

The ontogenetic spectrum of the CP in 2006 was established as left-sided with a peak in juvenile $(j)$ individuals, a gradual decrease in the proportion of individuals of subsequent states $\left(i m-g_{2}\right)$ and a sharp decrease in the proportion of old plants $\left(g_{3}-s s\right)$, which is consistent with the typical spectrum determined by biology of the species (Fig. a). The CP of A. pskemense in 2006 was noted as normal full-member. In 2016 it changed of the composition and was characterized as normal incomplete (the senile group was absent). Comparative analysis of individuals distribution on the CP in different years revealed changes in the structure of the CP. For 10 years, the peak from the juvenile group shifted to the young generative one, what says about gradual aging of the coenopopulation (Table) and indicates the irregularity of seed propagation. It is associated with the peculiarities of the species seed reproduction: low germination and outbreaks of phytophages, damaging up to $75 \%$ of seeds [5]. The recovery index decreased by more than four times. In addition, a high mortality rate of individuals at the early stages of ontogenesis is characterized for $A$. pskemense due to a weak root system, which is unable to quickly take root into the fine earth between stones. 
The development of a powerful root system and a gradual increase of the individual lifespan in the young generative state led to the predominance of this group at the CP. However, the rate of the CP development for 10 years did not exceed $1.5 \%$ per year. It reflect a slow change in the structure of the coenopopulation of this species when it grows on the scree. Thus, under the conservation regime, the existence of $A$. pskemense $\mathrm{CP}$ depends mainly on its replenishment with seed progeny, outbreaks of phytophagous pests, which sharply reduce the real seed productivity of individuals. The ecological density of individuals in the years under study varied slightly, averaging 7.1 (2006) and 9.8 (2016) individuals per $1 \mathrm{~m}^{2}$ and had an uneven distribution (1-34 ind. $\left./ \mathrm{m}^{2}\right)$.
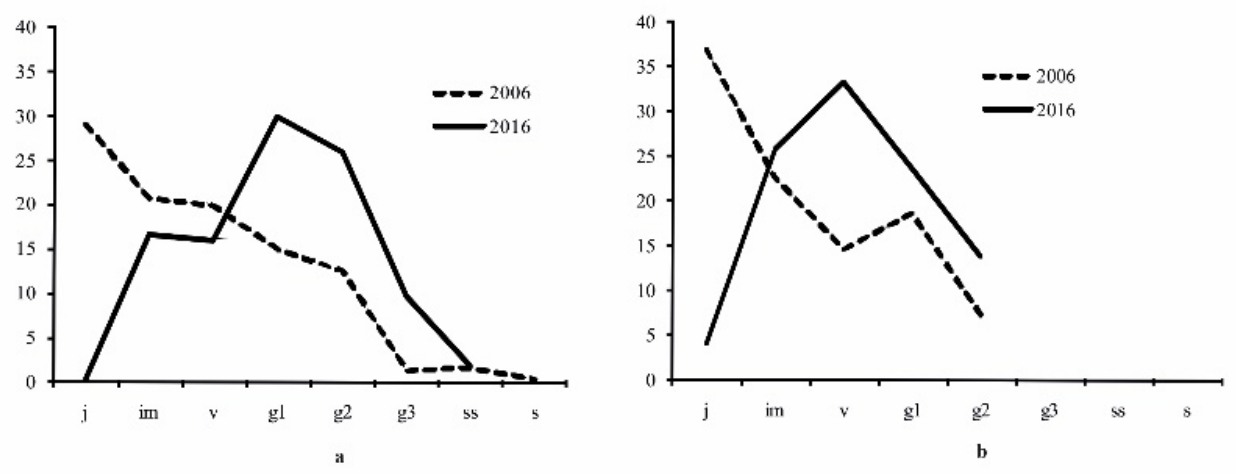

Fig. Ontogenetic spectra of Allium pskemense (а) и A. karataviense (b) coenopopulations

Legend: $\mathrm{X}$ axis, ontogenetic stages; $\mathrm{Y}$ axis, shares of various ontogenetic groups in the $\mathrm{CP}, \%$. Ontogenetic groups: $j$ - juvenale, $i m$ - immature, $v$ - virginal, $g_{1}$ - young generative, $g_{2}$ - mature generative, $g_{3}$ - old generative, $s s$ - subsenale, $s-$ senale.

Table. Demographic indicators and type of coenopopulation

\begin{tabular}{|c|c|c|c|c|c|c|c|}
\hline Species & Year & $\mathrm{D}_{\mathrm{e}}$ & $\omega$ & $\Delta$ & $\mathrm{I}_{\mathrm{r}}$ & $\begin{array}{c}\text { Type of } \\
\text { spectrum }\end{array}$ & $\begin{array}{c}\text { Type of the } \\
\text { CP }\end{array}$ \\
\hline \multirow{2}{*}{ A.pskemense } & 2006 & 7.1 & 0.4 & 0.17 & 1.4 & left-sided & young \\
\cline { 2 - 8 } & 2016 & 9.8 & 0.67 & 0.32 & 0.33 & left-sided & young \\
\hline \multirow{2}{*}{ A. karataviense } & 2006 & 9.8 & 0.29 & 0.10 & 0.74 & left-sided & young \\
\cline { 2 - 8 } & 2016 & 8.7 & 0.51 & 0.18 & 0.62 & left-sided & young \\
\hline
\end{tabular}

Note: $\mathrm{D}_{\mathrm{e}}$ - ecological density; $\omega$ - efficiency index; $\Delta$ - age index; $\mathrm{I}_{\mathrm{r}}-$ recovery index

A. karataviense is a bulbous, monocentric, particulate plant with an annual bulb [6]. The duration of ontogenesis is not less than 25-30 years, the duration of the pregenerative period is 5-8 years. Like many bulbous plants, there is no senile, less often the subsenile state. Self-preservation of the CP is carried out only by seed. Vegetative propagation is optional, it occurs in the mature generative state. The number of bulbs in a compact clone is no more than 2-4. There is no rejuvenation of ramets.

The CP of A. karataviense in 2006 was characterized as normal, incomplete (the old generative and postgenerative fractions were absent), the same structure was preserved in 2016. The ontogenetic spectrum of A. karataviense coenopopulation in 2006 was defined as left-sided with an absolute maximum at the juvenale group, what is indicates on successful seed regeneration of the species. This type of spectrum is characteristic of the $\mathrm{CP}$ of the Allium bulbous species [6]. A small local maximum on the young generative group was determined by the longer lifespan of individuals of this state in comparison with immature plants. In 2016, the ontogenetic structure of the coenopopulation underwent minor changes 
(Fig. b). While maintaining the left-sided spectrum type, the absolute maximum shifted to virginal individuals, the juvenale fraction decreased, and the share of the young and mature generation plants increased. The rate of The CP development was lower than that of $A$. pskemense and amounted to $0.8 \%$ per year. The ecological density of the species was low, 9.8 ind. $/ \mathrm{m}^{2}$ (table) and ranged from 1 to 39 individuals per $1 \mathrm{~m}^{2}$. Such a spread in the density of individuals is due to the peculiarities of the dispersion of seeds, namely, the concentration of the young plants near the mother, and the movement of the stony substrate.

Thus, analysis of the dynamics of the CPs of A.pskemense and A. karataviense showed that under the conditions of the reserve regime, a unidirectional change took place in the structure of the CPs towards their slow aging occurs, what reflects a large wave of development described by A.A. Uranov [8]. Successful seed renewal and reduction in the number of phytophages is necessary for the steady state of the $\mathrm{CP}$ and the regular turnover of generations of these species.

The authors are sincerely grateful to the staff of the Aksu-Zhabagly State Nature Reserve for their support in scientific research. The work was carried out within the framework of the state assignment (No AAAA-A21-121011290026-9) of the Central Siberian Botanical Garden of the SB RAS.

\section{References}

1. Red Book of Kazakhstan. V.2. Part 2. Plants (Astana, 2014)

2. A. I. Vvedensky, Flora of the USSR, 4, 113-280 (1935)

3. I. O. Baytulin, V. V. Lysenko, A. M. Nurusheva, Reports of NAS Rep. Kazakhstan, 6, 95-97 (2015)

4. Yu. A. Zlobin, V. G. Sklyar, A. A. Klimenko, Populations of rare plant species: theoretical foundations and methods of study (Sumy, 2013)

5. I. G. Levichev, L. S. Krasovskaya, Bul. MOIP. Dept. biol., 86, 105-112 (1981)

6. V. A. Cheryomushkina, Biology of Allium species in Eurasia (Novosibirsk, 2004)

7. L. A. Zhivotovsky, Rus. Ecol., 1, 3-7 (2001)

8. A. A. Uranov, Biol. Science, 2, 7-34 (1975)

9. L. A. Zhukova, Population life of meadow plants (Yoshkar-Ola, 1995) 